\title{
Chaos arising from the hydrological behaviour of a floodplain river during the last century
}

\author{
Federico Giri ${ }^{1}$ and Melina Devercelli ${ }^{1}$ \\ ${ }^{1}$ Instituto Nacional de Limnologia
}

November 12, 2021

\begin{abstract}
The hydrological regime is the main factor governing the functioning of floodplain rivers. A full comprehension of its dynamic leads to a better understanding of the system's behaviour and of the proper methods that must be used. We analysed the daily water level of the Paraná River during the last century at three gauge stations using linear and non-linear tools to characterise the hydrological dynamic and to analyse to what extent chaotic behaviour prevails. The three water level time series were characterised as non-linear and non-stationary by power spectrum, autocorrelation function, and surrogate test analyses. A strange attractor was developed when the phase space was reconstructed, having a low dimensional chaos supported by correlation dimension, positive maximum Lyapunov exponents, and recurrence quantification analysis. In line with this, the system resulted unpredictable with a threshold by sample entropy, and with an intermediate hydrological complexity, while Hurst exponent characterised the system as persistent and with sensitive dependence on initial conditions. In a general overview, all the evidence obtained indicates that the Paraná River's behaviour is at the edge of chaos. A latitudinal gradient of decreasing chaoticity was observed as the floodplain extent increased, whereas complexity was highest at the intermediate river station due to the inflow of tributaries with different hydrology. This paper attempts to offer some additional insights for understanding the hydrological behaviour of floodplain rivers and the proper methods to understand their complexity.
\end{abstract}

\section{INTRODUCTION}

Floodplain rivers are among the most complex freshwater systems (Thorp, Thoms \& Delong, 2006; Amoros \& Bornette, 2002). They configure a network of environments integrated by hydrological fluctuations in a unique system, where the main channel and multiple floodplain water bodies interact by lateral exchanges of water (Bayley, 1995). The hydrological regime is considered to be the factor that governs the functioning of the system and that maintains its ecological integrity (Power, 1995; Ward \& Stanford, 1995; Bellmore, Baxter, Martens \& Connolly, 2013). It connects biogeochemical processes (Tabacchi et al. , 1998; Fisher, Heffernan, Sponseller \& Welter, 2007; Hamilton, 2010), modulates the fate and storage of organic matter (Casco, Galassi, Mari, Poi \& Neiff, 2016; Mayora, Scarabotti, Schneider, Alvarenga \& Marchese, 2020), and enables the high biodiversity that these systems sustain with organism cycles coupled to a large extent to water level fluctuations (Neiff, 1990; Ward, Tockner \& Schiemer, 1999; Thomazet al. , 2007). Hence, understanding the hydrological dynamic is an important feature to partially elucidate the functioning of the river as well as the biological communities' assembly.

The hydrological dynamic is the result of a wide set of factors that act at different spatial and temporal scales. As regards the spatial scale, landscape and geomorphic elements model and are modelled by water (Schum \& Licht, 1965). Temporarily, long-term climate variability -such as the Atlantic Multidecadal Oscillation, and others of shorter-term, like the North Atlantic Oscillation, the Pacific Decadal Oscillation, and El Niño-Southern Oscillation- are forces that have shaped rivers hydrology during the last century (Probst \& Tardy, 1989; Puckridge, Sheldon, Walker \& Boulton, 1998; Millimam, Farnsworth, Jones, Xu \& Smith, 2008; Antico, Schlotthauer \& Torres, 2014; Robledo, Vera \& Olga, 2016). More frequent forces acting on river 
flows are seasonal dynamics, headwater and local rainfalls, water runoff from floodplains (Tavares Lima, Rosa, Ramos \& de Moraes Novo, 2003), sediments' transport (Sivakumar et al. , 2007), and also anthropogenic modifications such as dam regulation, infrastructure works, or flow bypass (Poff et al. , 1997; Pinter, 2005; Opperman et al. , 2009; Jardim et al. , 2020).

Linear and non-linear models are alternative approximations to capture the variability that results from the multiplicity of factors involved in hydrological behaviour (Sivakumar, 2016). Recently, it was stated that from the outcome of non-linear river dynamic, chaos is much more widespread than expected (Sivakumar, 2000, 2005; Sivakumar \& Jayawardena, 2002; Khokhlov, Glushkov, Loboda, Serbov \& Zhurbenko, 2008; Ghorbani, Khatibi, Sivakumar \& Cobb, 2010; Ghorbani, Asadi, Makarynskyy, Makarynska \& Yaseen, 2017; Khatibi et al. , 2012; Sivakumar \& Singh, 2012; Tongal \& Berndtsson, 2014). In general terms, chaotic deterministic systems are mainly characterised by high sensitivity to initial conditions (Wilks, 1991), instability, nonlinearity, and fractal symmetry, among others. They are systems that are constantly changing, with patterns that are never repeated in the same way but that develop within certain limits (attractor) and periodicity (Rosenstein, Collins \& De Luca, 1993; Lewin, 1999). Chaotic systems differ from random systems because they are susceptible to modelling, and predictable in the short term, as they arise from deterministic systems. But they are unpredictable in the long term, due to their sensitivity to the conditions under which the pattern was formed (Kantz \& Schriber, 2004). By contrast, random systems are irreproducible, not able to be modelled, and unpredictable. Stationarity or non-stationarity is another key property that describes the presence of regularities or irregularities in river dynamics, identifying the presence of rare events in the series under study (Kantz \& Schreiber, op cit.). Exploring the mentioned general properties of the systems' behaviour, among others, should give us a better idea of their functioning.

The Paraná River is the second largest river in South America and the fifth in the world. The main channel transports most of the water flow while the amount stored at the adjacent floodplain depends on the slope and spatial extent of the different river stretches. The hydrograph is characteristically variable with permanent fluctuations that lead to floods and droughts of different magnitude and duration (Neiff, Mendiondo \& Depetris, 1990; Depetris, 2007). This fluvial dynamic, together with the consequent spatiotemporal heterogeneity, makes the river a hotspot of biodiversity (Agostinho, Gomes, Veríssimo \& Okada, 2004). It is emplaced in an area of social and economic importance, it provides water and energy to the region through hydroelectric power, and it is used as a natural waterway. Therefore, the river constitutes a hotspot of ecosystem services (Viglizzo \& Frank, 2006), and the hydrological behaviour has become an issue of concern in theoretical and practical terms.

Several studies focused in analysing the hydroclimatic variability and water discharge trends of the Paraná River (e.g., García \& Vargas, 1998; Dettinger \& Diaz, 2000; Labat, Ronchail \& Guyot, 2005; Pasquini \& Depetris, 2007; Dai, Qian, Trenberth \& Milliman, 2009; Anticoet al. , 2014; Antico, Aguiar \& Amsler, 2018; Puig, Olguín Salinas \& Borús, 2016). Linkages were found between the river flow and sea surface temperatures (Mechoso \& Pérez Iribarren, 1992; Robertson \& Mechoso, 1998; Camilloni \& Barros, 2003) with changes in land coverage (Barros, Clarke \& Dias, 2006; Lee et al. , 2018). Precipitation regimes were related to interannual and interdecadal hydrological variability, and to the ENSO phenomenon (Aceituno, 1988; Ropelewski \& Halpert, 1987, 1989; Kiladis \& Diaz, 1989; Barros, Doyle \& Camilioni, 2008; Berri, Ghietto \& García, 2002; Boulanger et al. , 2005; Robledo, Vera \& Penalba, 2020).

With regards to the developed models, some of them analysed the long-term non-linear trend (Genta, PérezIribarren \& Mechoso, 1998; Robertson \& Mechoso, 1998), while many others were prompted to analyse flooding events or to solve flood-related problems (Neiff et al. , 2000; Depetris, 2007; Antico et al. , 2014). The effect of dam-regulation was also recently explored (Zanon, 2021). Nevertheless, according to our knowledge, the hydrology of the Paraná River was not studied under models that consider chaotic behaviour. We hypothesised that the Paraná fluvial system presents a chaotic dynamic due to the multiplicity of factors acting at different spatial and temporal scales on the hydrological regime. This would evidence a non-linear system at the edge of chaos (sensu Kauffman, 1993). Within this framework, the aim of our work was to analyse the hydrological behaviour of the Paraná River during the last century and to elucidate to what 
extent chaotic dynamics prevails. Daily variation of water level over 111 years was analysed for this purpose at three different river stretches. We selected water level to evaluate the behaviour of the system, since it is a variable sensitive to system changes and it directly reflects the hydrological connectivity. We additionally analysed water discharge, which is also a variable closely related to hydrological behaviour, but uncertainties inherent to its calculation process could be amplified in time series analyses introducing noise in the models (Khatibi et al. , 2011).

We performed different linear and non-linear techniques. They included power spectrum, autocorrelation function, surrogate test, mutual information function, and false nearest neighbour algorithm to explore time series data and to search for the parameters. Then, we used correlation dimension, sample entropy, maximal Lyapunov exponent, and Hurst exponent to identify system dynamics. By using this set of techniques, we looked for a consensus of results rather than focusing on one method.

\section{MATERIAL AND METHODS}

\section{The studied river and data}

The Paraná River flows latitudinally from North to South along $3800 \mathrm{~km}$, draining an area of $2.6 \times 10^{6}$ $\mathrm{km}^{2}$ (Fig. 1). The upper stretch of the river flows through an area of steep terrain that extends from the headwaters at the confluence of Grande and Paranaíba Rivers up to the confluence with the Paraguay River (Tossini, 1959). About 130 reservoir dams are operational in this stretch, modulating its discharge and sediment transport (Forget et al. , 2009). Downriver, the middle stretch begins, where the river reduces its general slope and receives throughout the Paraguay River a high amount of sediments coming from the Andean tributaries. A lateral floodplain of about 13 to $40 \mathrm{~km}$ wide is developed, which is characterised by multiple lotic and lentic water bodies. The lower stretch splits the mainstream in two arms, forming a delta at the end (Pasquini \& Depetris, 2007).

The studied time series were based on daily observations of water levels (HL) at three selected gauging stations located along the main channel of the Paraná River. Itatí Station is located in the upper stretch $\left(27^{\circ} 15^{\prime} 58.50^{\prime \prime} \mathrm{S}-58^{\circ} 14^{\prime} 39.50^{\prime \prime} \mathrm{W}\right)$, whereas Corrientes Station $\left(27^{\circ} 27^{\prime} 35^{\prime \prime} \mathrm{S}-58^{\circ} 49^{\prime} 60^{\prime \prime W}\right)$, and Túnel Subfluvial Station (Túnel, $31^{\circ} 43^{\prime} 11.50^{\prime \prime} \mathrm{S}-60^{\circ} 31^{\prime} 3.10^{\prime \prime} \mathrm{W}$ ) are located in the middle stretch of the river. Analyses were performed on a frequency of 7 and 15 days. Discharge variables were considered as well, in order to evaluate, with different parameters and evidence, the results reached with daily water level time series. The study covered a 111-year period, from 1910 to 2015 for Itatí Station, from 1904 to 1990 for Corrientes Station, and from 1904 to 2015 for Túnel Station. The three time series data sets were obtained from the integrated data base of COHIFE (Consejo Hídrico Federal, Secretaría de Infraestructura y Política Hídrica de la Nación Argentina, http://bdhi.hidricosargentina.gob.ar/).

\section{Data analysis}

First of all, we performed linear (power spectrum and autocorrelation function) and non-linear analyses (surrogate test) to evaluate the dynamic of the three hydrological time series using the package 'nonlinearTseries ', version 0.2.11 (García \& Sawitzki, 2021) under the software environment R (R Core Team 2021), as well as other analyses carried out in this work. The power spectrum and autocorrelation function were used as measures of the stationarity of time series. A time series is stationary if it is free of trend or seasonality, implying that the statistical parameters of the data remain constant through time, independently of which part of the time series are under consideration. If such parameters do not remain constant through time, then the time series is non-stationary (Sivakumar, 2016).

The power spectrum (PS) allows us to study the oscillations of the time series by the decomposition of variance as a function of frequency. As a requirement, the data set should cover a much longer stretch of time than the longest time scale, relevant for the evolution of the system (Sivakumar, 2016). The PS shows the contribution of possible periods, indicating the frequencies at which the variations are strong and weak. As a result, the time series is considered non-stationary if there is high power in the low frequencies (Kantz \& Schreiber, 2004). The PS was graphically performed using the R package 'psd', version 0.2.1.0 (Barbour, 
Kennel \& Parker, 2020).

Autocorrelation function (ACF) measures the internal correlation within a time series. It was performed to determine the degree of dependence present in the values. Stationary series have a constant value of ACF over time whereas decaying values are indicative of non-stationary series.

The surrogate data testing was performed to contrast the null hypothesis that data come from a linear stochastic process. The method generates a surrogate data set which is consistent with the null hypothesis, and finally computes a discriminant statistic for the original data set and for each one of the surrogate ones. If the value computed for the original data set is significantly different from the ensemble of values computed for the surrogate data sets, then the null hypothesis is rejected, and non-linearity is assumed (Theiler, Eubank, Longtin, Galdrikian \& Farmer, 1992).

Subsequently, we searched the parameters in order to evaluate the dynamic of the time series with appropriate methods for non-linear and large data sets. The delay time (time lag, $\tau$ ) was calculated using the average mutual information function (AMI). This function estimates a suitable time lag at which the time series has to be plotted against itself (Frazer \& Swinney, 1986). We used the first.e.decaymethod that selects the $\tau$ values where the AMI function decays to 1/e of its value at lag zero (García \& Sawitzki, 2021).

False nearest neighbour method (FNN) was applied as a technique to estimate the minimal embedding dimension $m$ (Ghorbani et al. , 2010). The method assumes that two points are neighbours if they remain close when dimension increases. Hence, it examines the number of neighbours in increasing embedding dimension until it finds a dimension where the effect of false neighbours is trivial. An appropriate embedding dimension is determined by checking how the neighbours change as a function of dimension (Krakovská, Mezeiová \& Budáčová, 2015).

Noise reduction was performed to decompose each value of the time series into two components: one that contains the signal, and another one that contains the random fluctuation. We evaluated the noise of the data series at different radii and, finally, we selected the most representative series with reduced noise at each sample site (Kantz \& Schreiber, 2004).

The nature of a dynamical system can be modelled by a phase space diagram (Ghorbani et al. , 2017). We reconstructed the phase space of each one of the three-time series using the Takens' theorem to obtain the geometric structure of the multidimensional dynamic or attractor. This method constructs two fictitious observables from the original time series by displacing time intervals. The attractor was built in three dimensions, by using the embedding dimension $\mathrm{m}$ and the delay time $\tau$ parameters (Takens, 1981), and it was implemented by using the package 'plot3D', version 1.3 (Soetaert, 2021). With the three noise-free time series, we evaluated and identified the degree of chaos present in the water level dynamic of the Paraná River. For this purpose, we computed correlation dimension, sample entropy, maximal Lyapunov exponent, and Hurst exponent.

The correlation dimension $\left(\mathrm{D}^{2}\right)$ is a non-linear measure of an attractor dimension that indicates the correlation between pairs lying in the phase space (Khatibi et al. , 2012). This $\mathrm{D}^{2}$ method involves the reconstruction of phase space at different embedding dimensions (Grassberger \& Procaccia, 1983a; Kantz \& Scheriber, 1997). Chaotic deterministic and random processes are differentiated by $\mathrm{D}^{2}$ because, in the former, it varies linearly with an increasing $\mathrm{m}$ and saturates after a certain value; whereas, in the latter, it varies linearly without reaching a saturation value. In this analysis, we also considered the Zounemat-Kermani (2016) criterion (inspired in Casdagli, 1992) which characterises the system as low-dimensional ( $\mathrm{D}^{2}[?]$ 3.0) or high dimensional $\left(\mathrm{D}^{2}>3\right)$ chaoticity.

The sample entropy (hq) or Kolmogorov-Sinai entropy was assessed to measure the unpredictability of the time series using the $\mathrm{D}^{2}$ sum (Grassberger \& Procaccia, 1983b). This method measures the rate of information produced by the system. The entropy value $\mathrm{K}=0$ is indicative of periodic or quasi-periodic time series (completely predictable); $\mathrm{K}=[?]$ indicates white noise (unpredictable by definition); and $0<\mathrm{K}$ $<$ [?] indicates chaotic deterministic system (unpredictable with a threshold) (Kantz \& Schreiber, 2004). 
The recurrence quantification analysis $\left(\mathrm{M}_{\mathrm{i}, \mathrm{j}(\mathrm{r})}\right)$ was performed to quantify the number and duration of the recurrences in the phase space and to graphically identify, with the recurrence plot, if the dynamic of the system's behaviour is periodic, random, or chaotic. A recurrence is the trajectory return to a neighbourhood of a region that was visited before in the phase space. For this, the computation of the recurrence matrix was required (Garcia et al. , 2017).

The recurrence plot is graphically defined on the trajectory of the underlying system phase space, which is used to extract qualitative characteristics of a dynamical system (Eckmann, Kamporst \& Ruelle, 1987). It represents distance correlations of a time series in a two-dimensional graph. Recurrence plots were constructed for each time series using the embedding dimension and the delay time values already detailed above, and were implemented with the 'tseriesChaos' package, version 0.1-13.1 (Di Narzo, 2013). They were performed as an array of a matrix $(N i \times N j)$, where $\mathrm{N}$ is the number of states of the systems $(i, j=1$, $\ldots, N$ ). Similar states (minor transition or lower distance) were indicated by a zero in the matrix, whereas different states (major transition or higher distance) were indicated with a one (Marwan, Romano, Thiel, \& Kurths, 2007). According to the way in which patterns are presented in the recurrence plot, it is possible to identify: I) homogeneous recurrence plots (uniformly distributed noise), that are typical of stationary random time series; II) diagonal oriented, periodic or quasi-periodic recurrent structures of recurrence plots, that are representative of periodic or quasi-periodic systems (super-positioned harmonic oscillations); III) drift structures (logistic map corrupted with a linearly increasing term), that are particular of slowly varying parameters like non-stationary systems; and IV) disrupted recurrence plots with white areas of bands, characteristic of systems with abrupt changes in the dynamics (Brownian motion) (Marwan et al. , 2007).

The maximal Lyapunov exponent $(\lambda)$ was performed as a measure of the strength of chaos. It quantifies the exponential rate by which two typical nearby trajectories diverge in time (Kantz \& Schreiber, 2004). Also, the Lyapunov exponent is a measure of the sensitivity of a dynamical system to initial conditions, a characteristic of chaotic systems (Taylor, 2010). A system with at least one positive Lyapunov exponent is defined to be chaotic. The attractor presents trajectories that diverge, on average, at an exponential rate characterised by the largest Lyapunov exponent (Rosenstein et al. , 1993). We computed the $\lambda$ for 15 different embedding dimensions to evaluate its invariance and non-dependence (García et al. , 2017).

Finally, the Hurst exponent $(\mathrm{H})$ which measures the intensity of long-range dependence in a time series (Hurst, 1951) was performed by using the modification proposed by Weron (2002). The H parameter indicates the persistence of the system and shows to which extent it is resistant to changes in the face of external stimuli. Persistence $(0.5<\mathrm{H}<1)$ means that the series has a clear tendency and that it is retained for a long period of time. Hence, the response is not a consequence of an instantaneous stimulus, but it rather depends on its prior history. Anti-persistence $(0<\mathrm{H}<0.5)$ is the tendency to constantly return to the point of origin (Gavilan-Moreno, 2010) and, therefore, the instantaneous stimulus is important. Persistence and anti-persistence are characteristics of a chaotic and random dynamical system, respectively. $\mathrm{H}$ is also related to the autocorrelation and the fractal dimension of the time series (Ekeet al. , 2000). In this study, $\mathrm{H}$ was evaluated at different window's length $\mathrm{d}$ (from 50 to 10000) that slid through the data series using the corrected empirical $\mathrm{H}$, and finally, a $d=60$ was selected. The package 'pracma', version 2.2.9 was used to implement $\mathrm{H}$ analysis (Borchers, 2019).

The equations used for sample entropy, recurrence quantification analysis, maximum Lyapunov exponent, and Hurst exponent are indicated in Supplementary Methods S1.

\section{RESULTS}

The Paraná River exhibited a fluctuating hydrological regime at the three gauging stations (Fig. 1), with periods of high and low waters that alternated with peaks of extreme values of water level that represent extraordinary floods and droughts (Fig. 2a). Mean water level was approximately $3.3 \mathrm{~m}$ at Corrientes and Itatí stations, and it slightly decreased down river, at Túnel Station (Table 1).

The power spectrum presented high energy at low frequencies (much power), and then it was asymptotic at higher frequencies (Fig. 2b), indicating non-stationary time series. Few peaks were observed in the signal. 
The shape of the curves and the spectrum shown in the graphs were indicative of non-linearity. Similarly, the autocorrelation function accounted for a slow autocorrelation decay in the three-time series and, hence, these were considered non-stationary (Fig. 2c).

Surrogate data analyses revealed that the original data sets were significantly larger than surrogate data. We rejected the null hypothesis that data come from linear stochastic processes, and non-linearity was assumed for the time series of the three hydrological gauging stations (Fig. S1).

According to those results, the parameter reconstructions of the time series were adequately performed by using methods for non-linear systems. The determination of the delay time for the phase space reconstruction by means of the average mutual information (AMI) function was calculated at a lag of 300 days. The first local minimum values for the AMI function were 6,8 and 12 days for Itatí, Corrientes and Túnel gauge stations, respectively (Fig. S2). An embedding dimension $\mathrm{m}$ of 10 was sufficient to explain the dynamic of the daily water level data for Itatí Station, whereas a value of 8 was adequate for Corrientes, and of 5 for Túnel Station (Fig. S3).

Noise in time series was found to be almost imperceptible in the three data sets by observing the attractor's shapes at different radii. Hence, we performed the denoise of the time series with a radius of 1 . The subsequent analyses to identify possible chaotic dynamics were run with the denoised time series.

A clear attractor in a well-defined region emerged from the phase space reconstruction of the three-time series. We inferred, according to the shape of the attractor, that the system is low dimensional chaos (Fig. 3 ). Comparing the three-time series, the orbits of the attractor were more similar in both northern stations than in the southern station.

The correlation dimension $\left(\mathrm{D}^{2}\right)$ values suggested a chaotic deterministic behaviour of the water level time series at the three river stations. The values of $\mathrm{D}^{2}$ in the graphs stabilised after $\mathrm{m}$ reached a certain value which is indicative of the existence of chaos in time series (Fig. 4). $\mathrm{D}^{2}$ values varied among 2.4 and 3.3 (Table 2). Thus, according to the $\mathrm{D}^{2}$ values, the hydrological regime of the Paraná River was characterised as having different dimensional chaoticity. If we analyse in detail the behaviour at each river's gauging station, we observe a latitudinal gradient from low to high dimensional chaoticity of daily water level time series.

The sample entropy revealed that the water levels at the three river stations had positive values (Table 2), providing evidence about the unpredictability with a threshold of the system. Túnel Station presented the lowest $\mathrm{K}$ value, being highest at Corrientes and intermediate at Itatí Station (Table 2).

The recurrence quantification analysis showed that the time series of Túnel has a higher recurrence value $(\mathrm{REC}=0.128828)$ than the time series of Corrientes $(\mathrm{REC}=0.05294243)$ and Itatí $(\mathrm{REC}=0.04802505)$. Regarding the percentage of recurrence points that form diagonal lines (DET), the three time series had high DET values (Túnel $=0.995422$, Corrientes $=0.9861203$, Itatí $=0.983693$ ). The maximum length of the longest diagonal line (MDL), excluding the main diagonal (Túnel $=28.05198$; Corrientes $=15.30455$; Itatí $=15.53112)$, and the average diagonal lines $(\mathrm{ADL}$ : Túnel $=28.04659$; Corrientes $=15.29503$; Itatí = 15.52243) revealed similar patterns than the ones observed in the REC values at the three river stations (Fig. 5, Table S1).

Comparing and interpreting the recurrence plots of the three time series, we observed that they present similar patterns (Fig. 5) corresponding to a superposition of patterns II (periodic or quasi-periodic) and III (non-stationary systems). The examination of these plots revealed the existence of short line segments parallel to the diagonal of the recurrence plots, which are related to the inverse of the largest positive Lyapunov exponent. Once again, we found a latitudinal pattern indicating that the northern station presented a major transition in the process (Itatí Station, more different states) than the southern station (Túnel Station, more similar states), whereas the middle station (Corrientes) presented an intermediate transition pattern. In random time series, these short line segments would not be observed.

The maximal Lyapunov exponent presented positive values $(\lambda>0.03)$ for the three-time series (Table 2 ). 
This means an exponential divergence of nearby trajectories that is interpreted as low-dimensional chaos. Itatí Station data set presented the highest $\lambda$-value, whereas Corrientes presented an intermediate value, and Túnel the lowest value (Table 2).

According to the Hurst exponent, the time series revealed a persistent behaviour $(\mathrm{H}>0.5)$, indicating that the system has a trend according to their state (Table 2). The river stations presented a latitudinal pattern where $\mathrm{H}$ increased downriver.

\section{DISCUSSION}

According to our hypothesis, the hydrological fluctuations of theParaná River present a behaviour that is at the edge of chaos. In a general overview of our study, all the evidence obtained indicates a low to high dimensional chaos. The analyses were performed on daily water level variations, recorded during the last century at three different river stations. Additionally, we evaluated the behaviour of the river in other coarser time frequencies ( 7 and 15 days) and on water discharge data (Table S2, S3), arriving to similar results. These findings reinforce the idea that the Paraná River has a chaotic dynamic, independently of the temporal interval (1, 7 or 15 days) and variable (water level or water discharge) used.

Considering the general chaotic dynamic observed in the hydrological regime of the Paraná, we found similar behaviour in other floodplain rivers, such as the Mississippi and Chao Phraya (Sivakumar et al. , 2007), and in rivers with different morphological characteristics (Porporato \& Ridolfi, 1997; Ghorbani et al. , 2010; Khatibiet al. , 2012; Kedra, 2014; Albostan \& Onoz, 2015; Adenan, Hamid, Mohamed \& Noorani, 2017; Salter, Voller \& Paola, 2020). Also, the analyses of the channel pathway of floodplain rivers exhibited chaotic behaviour (Zibret \& Verbovsek, 2008).

The time series used in our study were large enough and had low or negligible noise, emphasising the robustness of our data set and overcoming potential issues of short and noisy series in which estimators could have erratic fluctuations into signalling chaos (Theiler et al. , 1992). Noise reduction over the time series did not evidence differences with the original data, confirming that the time series were not characterised by high noise. Then, noise reduction enabled us to preserve non-linear interactions, as an important way of maintaining the deterministic nature of the hydrological variability in the context of chaos theory (Porporato \& Rodolfi, 1997).

The preliminary analyses, power spectrum (PS), autocorrelation function (ACF), and surrogate test, performed to evaluate the nature of the Paraná River's system dynamic revealed that water level time series at the three stretches correspond to non-linear and non-stationary processes. The PS presented the information in the frequency domain while the ACF presented it in the time domain. Although Sivakumar (2000) and Kantz \& Schreiber (2004) affirm that signal and noise are readily distinguished in the PS, we agree that both analyses are not appropriate enough to distinguish between random and chaos, and should be used as a first evaluation of the characterisation of time series. Since the ACF only measures the linear dependency between the variables, it is not necessarily suitable for non-linear systems that can better catch the realm of hydrological complexity (Abarbanel, Brown, Sidorowich \& Tsimring, 1993; Frazer \& Swinney, 1986). In this regard, the surrogate test provides a strict statistical approach (Theiler et al., 1992; Schreiber, 1999; Luo, Nakamura \& Small, 2005) to definitely reject the hypothesis of linearity of the hydrological processes. Nevertheless, linear tools in combination with non-linear methods are still useful in the overall scheme of systems evaluation to provide evidence about seasonal and annual cycles, long-term persistence, and scale invariance (Sivakumar et al. , 2007).

The slow decay of the ACF also shows that future values of the time series heavily depend on past values, and the mean will change over time, indicating the non-stationary nature of the time series. The properties of the dynamic found at Paraná River give evidence to move forward from the traditional stationary and lineal approaches used in hydrology as other authors already did (e.g., Sivakumar, 2016; Poff, Tharme \& Arthington, 2017), settling the possibility to implement a different universe of analyses in order to properly understand the nature of the system. 
Assessing the occurrence of non-stationary patterns allows a meaningful understanding of the hydrological regime in the frame of changes in the Paraná basin such as meteorological extremes (Xavier et al. , 2020) and land uses (Lee et al. , 2018). It is also an opportunity to evolve in recognising the non-stationarity of many ecological systems (Poff et al. , 2017) from which the water regime is the driving factor (Thomaz et al. , 2007; Webb, Stewardson \& Koster, 2010; Arthington, Naiman, Mcclain \& Nilsson, 2010; Devercelli, Scarabotti, Mayora, Schneider \& Giri, 2016).

In this sense, the phase space reconstruction and the correlation dimension are more adequate analyses for system identification than the commonly used linear tools. The phase space reconstruction reveals that the Paraná River is characterised by a strange attractor having a low dimensional chaos. In a chaotic system, orbits of an attractor are non-periodic; that is to say, there are points anywhere in space that are never visited more than once, and there are regions that are never visited at all. Those sets of points are fractal in their nature and have a non-integer dimension (Taylor, 2010). The fractal structure of the studied time series was also evidenced by the results obtained in the analyses of correlation dimension, Lyapunov exponent, sample entropy, and Hurst exponent, and contributes to gain an insight into chaotic dynamics (Serquina, Lai \& Chen, 2008).

The strange attractor in which the Paraná system evolves resembles that of other large rivers (Sivakumar, Jayawardena \& Li, 2007). Investigations of various hydrological time series also suggest that strange attractors are far more prevalent in fluvial systems when compared to point attractor and limit cycle (Ghorbani et al. , 2010; Khatibi et al. , 2012; Sivakumar, 2016). In the space-time movement of the attractor at the three river stations we observed a spatially coherent distribution, where the hydrological regime presents periods of high and low waters with extraordinary periods of both floods and droughts.

The orbits of the strange attractor have a limited predictability of the system, which is defined by global and local Lyapunov exponents (Khokhlov et al. , 2008). The maximum Lyapunov exponent of the Paraná time series indicates that the trajectories of the attractor diverge in a dissipative way, with values that confirm the behaviour in the edge of chaos of the hydrological processes, as it was observed in previous results. In line with this, the positive value of sample entropy showed that the system is unpredictable with a threshold. As a measure of complexity (Belot \& Earman, 1997), sample entropy also denotes an intermediate hydrological complexity, which is another element for understanding the chaotic dynamic of the Paraná River hydrology. Considering the Hurst exponent, it allows us to characterise our system as persistent, having a long-term memory. This implies that the present state of the system will impact on its future state (Peters, 1994). That is, if the water level begins to increase, it tends to continue increasing for an indeterminate period ( $a$ priori ) and then, suddenly, the tendency can change. After that, the water level began to decrease, acquiring a new tendency. As in other rivers, the long-term persistence behaviour supported by an estimated Hurst exponent provides insight for hydrology understanding, as well as for linking hydrology with the transport of sediments and flow management (Maftei, Barbulescu \& Carsteanu, 2016; Adarsh et al. , 2020). Hurst values also evidenced that the system is chaotic since they showed sensitive dependence on initial conditions.

A guiding principle of the study of the hydrological behaviour of rivers is that it constitutes the 'master factor' that regulates many others (Power, 1995). In floodplain systems, such as the Paraná River, ecological functioning, biodiversity patterns, and cycles of biological communities mainly depend on the hydrological regime (Junk, Bayley \& Sparks, 1989; Neiff, 1990; Bunn \& Arthington, 2002; Thomaz et al. , 2007). Investigating the complexity of the hydrological processes is fundamental for developing a proper planning and managing of rivers (Ma et al. , 2020), and for understanding the underlying processes of diversity assembly (Devercelli et al. , 2016). Medvinskyet al. (2001) pointed out the importance of chaotic regimes in the organization of aquatic ecosystems. The higher potential of adaptation to changes of chaotic systems in comparison to others that have a stable equilibrium point is well-known (Hastings, Hom, Ellner, Turchin \& Godfray, 1993; Huisman \& Weissing, 1999; Benincà et al. , 2008).

As regards the longitudinal dimension of the Paraná River, a spatial difference was found in the characterisation of the hydrological behaviour as it was observed in other rivers (Kedra, 2014; Ma, Kang \& Song, 2020). The Hurst exponent revealed a latitudinal gradient from less to more persistence system dynamic. 
Also, $\mathrm{D}^{2}$ and maximum Lyapunov exponent were the highest in Itatí, intermediate in Corrientes, and the lowest in Túnel stations, showing the same decreasing gradient in the chaotic behaviour (Table 2). These parameters might be evidencing the effect of river morphology that has a gradually larger extent of its floodplain from Itatí to Túnel stations. In this regard, floodplain influences hydrological fluctuations by retaining water and could, therefore, act by dampening the chaoticity and increasing the persistence downriver, as its development increases. In addition, the floodplain effect on the hydrological fluctuations was also observed since floods with multiple peaks in Corrientes Station tend to lose these characteristics downriver (Cristina \& Ramonell, 2018).

On the other hand, the highest complexity shown by the sample entropy values was found at the latitudinally intermediate river station. The confluence of rivers with different regimes might be adding hydrological complexity to this stretch: the Bermejo River originating in the western Andean Mountain flows into the Paraguay River, which upper catchment is in the Brazilian Pantanal and flows into the Paraná (Figure 1). Nevertheless, the tributaries' influence has just a local effect on the water level (Ramonell \& Cristina, 2014).

As a general overview, there are many factors influencing the complexity and chaotic dynamic of rivers, and they vary in the longitudinal gradient (Ma et al. , 2020). Some factors are inherent to the configuration of rivers, such as geomorphology, topography, sediment transport, inflow composition, and vegetation (Tabacchi et al. , 1998; Poff, Olden, Pepin, \& Bledsoe, 2006); while other factors are external to the configuration of rivers, such as meteorological factors (precipitation, temperature, atmospheric pressure) and anthropic interventions (McManamay, Bevelhimer \& Kao, 2014). In the case of the Paraná River, the meteorological component has the main modulating effect on the overall hydrological regime that mainly depends on the precipitation of the upper basin located in Brazil (Berbery \& Barros, 2002). They are combined with local conditions that may not contribute to spatial differences in the case of the stations studied (Amsler, Ramonell \& Toniolo, 2005). On the contrary, the geomorphology and tributary inflows might be important factors influencing the latitudinal differences observed (Ramonell \& Cristina, 2014). Vegetation development and sediment transport might also have its effect, since both are associated with those characteristics. Additionally, vegetation has its own influence due to its modelling role on hydro-geomorphological features (Ramonell, Marchetti \& Pereira, 2013; Marchetti, Ramonell, Brumnich, Alberdi \& Kandus, 2020). These factors denote that water level behaves in the domain of deterministic chaos and intermediate complexity with variable strength in the longitudinal gradient of the river according to spatial heterogeneity.

Conclusion

Throughout this work, we evidenced, by daily time series analyses of water level, that the hydrological regime of the Paraná River has a chaotic deterministic behaviour in the edge of chaos. This dynamic was discovered by evaluating multiple analyses, exposing the robustness of our results for elucidating system dynamics. Particularly, hydrological fluctuations are characterised by non-linear and non-stationary processes. A strange attractor was revealed when the phase space was reconstructed, having a low dimensional chaos, supported by correlation dimension, Lyapunov exponent, sample entropy, recurrence quantification analysis, and Hurst exponent.

The obtained evidence showed differences from high to low dimensional chaos considering the three different river stations. This changing pattern is associated with the floodplain effect because the stations were located in sections of the river with different morphological characteristics and with the effect of the Paraná River tributaries.

Considering that the hydrological regime is the main factor governing the functioning of floodplain rivers, knowing the dynamics of hydrology helps us gather information at system scale that is relevant to understand different process, e.g., the dynamic of hydrological events such as floods and droughts, its implication in ecological processes that are associated to the maintenance of biodiversity, among others. Complexity and chaotic behaviour arising from the Paraná hydrological regime may be vital for sustaining biodiversity and system health.

The method employed in this article can be further applied to the analysis of other hydrological systems, 
evidencing the existence of deterministic chaos in natural environments. We argue that chaos theory offers a better understanding of hydrological systems than the more commonly used deterministic/stochastic paradigm.

\section{ACKNOWLEDGEMENTS}

We wish to thank Constantino A. García for helping us with noise analysis of the hydrological time series.

\section{DATA AVAILABILITY STATEMENT}

Data used in this study are available upon request. Raw data were obtained from http://bdhi.hidricosargentina.gob.ar/.

\section{CONFLICTS OF INTEREST}

Authors declare that there is no conflict of interest that affects the impartiality of the reported research.

\section{FUNDING INFORMATION}

This work was supported by PIP 2014-0716 PI M. Devercelli, Consejo Nacional de Investigaciones Científicas y Técnicas (CONICET).

\section{REFERENCES}

Abarbanel, H. D., Brown, R., Sidorowich, J. J., \& Tsimring, L. S. (1993). The analysis of observed chaotic data in physical systems. Reviews of modern physics , 65 (4), 1331. https://doi.org/10.1103/RevModPhys.65.1331

Aceituno, P. (1988). On the functioning of the Southern Oscillation in the South American sector. Part I: Surface climate. Monthly Weather Review , 116 (3), 505-524. https://doi.org/10.1175/15200493(1988)116\%3C0505:OTFOTS\%3E2.0.CO;2

Adarsh, S., Dharan, D. S., Nandhu, A. R., Vishnu, B. A., Mohan, V. K., \& Watorek, M. (2020). Multifractal description of streamflow and suspended sediment concentration data from Indian river basins. Acta Geophysica, 1-17.

Adenan, N. H., Hamid, N. Z. A., Mohamed, Z., \& Noorani, M. S. M. (2017). A pilot study of river flow prediction in urban area based on phase space reconstruction. AIP Conference Proceedings ,1870 , 040011. https://doi.org/10.1063/1.4995843

Agostinho, A. A., Gomes, L. C., Veríssimo, S., \& Okada, E. K. (2004). Flood regime, dam regulation and fish in the Upper Paraná River: effects on assemblage attributes, reproduction and recruitment. Reviews in Fish biology and Fisheries, 14 (1), 11-19.

Albostan, A., \& Önöz, B. (2015). Implementation of chaotic analysis on river discharge time series. Energy and Power Engineering , 7 (3), 81. DOI: 10.4236/epe.2015.73008

Amoros, C., \& Bornette, G. (2002). Connectivity and biocomplexity in waterbodies of riverine floodplains. Freshwater biology 47 (4), 761-776.

Amsler, M. L., Ramonell, C. G., \& Toniolo, H. A. (2005). Morphologic changes in the Paraná River channel (Argentina) in the light of the climate variability during the 20th century. Geomorphology ,70 (3-4), 257-278.

Antico, A., Aguiar, R. O., \& Amsler, M. L. (2018). Hydrometric data rescue in the Paraná River Basin. Water Resources Research ,54 (2), 1368-1381.

Antico, A., Schlotthauer, G., \& Torres, M. E. (2014). Analysis of hydro-climatic variability and trends using a novel empirical mode decomposition: application to the Paraná River Basin. Journal of Geophysical Research: Atmospheres , 119 (3), 1218-1233. https://doi.org/10.1002/2013JD020420 
Arthington, Á. H., Naiman, R. J., Mcclain, M. E., \& Nilsson, C. (2010). Preserving the biodiversity and ecological services of rivers: new challenges and research opportunities. Freshwater Biology ,55 (1), 1-16. https://doi.org/10.1111/j.1365-2427.2009.02340.x

Barros, V. R., Doyle, M. E., \& Camilloni, I. A. (2008). Precipitation trends in southeastern South America: relationship with ENSO phases and with low-level circulation. Theoretical and Applied Climatology ,93 (1), 19-33.

Barros, V., Clarke, R., \& Dias, P. S. (2006). Climate change in the La Plata basin. Publication of the Inter-American Institute for Global Change Research (IAI), São José dos Campos, Brazil.

Barbour A. J., Kennel, J, \& Parker, R. L. (2020). Adaptive, Sine-Multitaper Power Spectral Density and Cross Spectrum Estimation. 'psd' R package. Version 2.1.0.

Bayley, P. B. (1995). Understanding large river: floodplain ecosystems.BioScience , 45 , 153-158.

Bellmore, J. R., Baxter, C. V., Martens, K., \& Connolly, P. J. (2013). The floodplain food web mosaic: a study of its importance to salmon and steelhead with implications for their recovery. Ecological Applications , 23 (1), 189-207.

Belot, G., \& Earman, J. (1997). Chaos out of order: Quantum mechanics, the correspondence principle and chaos. Studies in History and Philosophy of Science Part B: Studies in History and Philosophy of Modern Physics , 28 . DOI: 10.1016/s1355-2198(96)00025-1

Benincà, E., Huisman, J., Heerkloss, R., Jöhnk, K. D., Branco, P., Van Nes, E. H., . . \& Ellner, S. P. (2008). Chaos in a long-term experiment with a plankton community. Nature, 451 (7180), 822-825.

Berbery, E. H., \& Barros, V. R. (2002). The hydrologic cycle of the La Plata basin in South America. Journal of Hydrometeorology ,3 (6), 630-645. https://doi.org/10.1175/15257541(2002)003\%3C0630:THCOTL\%3E2.0.CO;2

Berri, G. J., Ghietto, M. A., \& García, N. O. (2002). The influence of ENSO in the flows of the Upper Paraná River of South America over the past 100 years. Journal of Hydrometeorology , 3 (1), 57-65. https://doi.org/10.1175/1525-7541(2002)003\%3C0057:TIOEIT\%3E2.0.CO;2

Boulanger, J. P., Leloup, J., Penalba, O., Rusticucci, M., Lafon, F., \& Vargas, W. (2005). Observed precipitation in the Paraná-Plata hydrological basin: long-term trends, extreme conditions and ENSO teleconnections. Climate dynamics , 24 (4), 393-413. DOI: 10.1007/s00382-004-0514-x

Borchers, H. W. (2021). Practical Numerical Math Functions. 'pracma' R package. Version 2.3.3

Bunn, S. E., \& Arthington, A. H. (2002). Basic principles and ecological consequences of altered flow regimes for aquatic biodiversity. Environmental management, 30 (4), 492-507.

Camilloni, I. A., \& Barros, V. R. (2003). Extreme discharge events in the Paraná River and their climate forcing. Journal of Hydrology ,278 (1-4), 94-106.

Casco, S. L., Galassi, M. E., Mari, E. K., Poi, A. S., \& Neiff, J. J. (2016). Linking hydrologic regime, rainfall and leaf litter fall in a riverine forest within the Ramsar Site Humedales Chaco (Argentina).Ecohydrology, 9 (5), 773-781.

Casdagli, M. (1992). Chaos and deterministic versus stochastic non-linear modelling. Journal of the Royal Statistical Society: Series B (Methodological) , 54 (2), 303-328. https://doi.org/10.1111/j.25176161.1992.tb01884.x

Dai, A., Qian, T., Trenberth, K. E., \& Milliman, J. D. (2009). Changes in Continental Freshwater Discharge from 1948 to 2004. Journal of Climate, 22 (10), 2773-2792. https://doi.org/10.1175/2008JCLI2592.1

Cristina, I. M., \& Ramonell, C. G. (2018). Traslacion de ondas de crecida pre-1970 vs. post-1990 en el tramo medio del rio Parana. XXVIII Congreso Latinoamericano de Hidraulica. Buenos Aires, Argentina. 
Di Narzo, A. F. (2013). Analysis of nonlinear time series. 'tseriesChaos' R Package. Version 0.1-13.

Depetris, P. J. (2007). The Parana River under extreme flooding: a hydrological and hydro-geochemical insight. Interciencia ,32 (10), 656-662.

Dettinger, M. D., \& Diaz, H. F. (2000). Global characteristics of stream flow seasonality and variability. Journal of hydrometeorology , 1 (4), 289-310. https://doi.org/10.1175/15257541(2000)001\%3C0289:GCOSFS\%3E2.0.CO;2

Devercelli, M., Scarabotti, P., Mayora, G., Schneider, B., \& Giri, F. (2016). Unravelling the role of determinism and stochasticity in structuring the phytoplanktonic metacommunity of the Parana River floodplain. Hydrobiologia, 764 (1), 139-156.

Eckmann, J. P., Kamporst, S., \& Ruelle, D. (1987). Recurrence plots of dynamical systems. Europhysics Letters , 4 , 973-977. http://dx.doi.org/10.1209/0295-5075/4/9/004

Eke, A., Herman, P., Bassingthwaighte, J., Raymond, G., Percival, D., Cannon, M., \& Ikrenyi, C. (2000). Physiological time series: distinguishing fractal noises from motions. Pflugers Archiv , 439 (4), 403-415. DOI: $10.1007 / \mathrm{s} 004249900135$

Fisher, S. G., Heffernan, J. B., Sponseller, R. A., \& Welter, J. R. (2007). Functional ecomorphology: feedbacks between form and function in fluvial landscape ecosystems. Geomorphology, 89 (1-2), 84-96.

Forget, M. E. (2021). Les grands projets hydroelectriques du rio Parana, potentiels et devenir. Geocarrefour 84, 1-2. https://doi.org/10.4000/geocarrefour.7195

Fraser, A. M., \& Swinney, H. L. (1986). Independent coordinates for strange attractors from mutual information. Physical review A , 33 (2), 1134.

Garcia, C. A., \& Sawitzki, G. (2021). Nonlinear Time series analysis. 'nonlinearTseries' R package version $0.2,11$.

Garcia, C. A., Quintana, A. O., Vila, X. A., Tourino, M. J. L., Rodriguez-Linares, L., Presedo, J. M. R., \& Penin, A. J. M. (2017). Heart rate variability analysis with the R package RHRV. Cham, Switzerland: Springer International Publishing.

Garcia, N. O., \& Vargas, W. M. (1998). The temporal climatic variability in the 'Rio de la Plata' basin displayed by the river discharges. Climatic Change , 38 (3), 359-379.

Genta, J. L., Perez-Iribarren, G., \& Mechoso, C. R. (1998) A recent increasing trend in the streamflow of rivers in southeastern South America. Journal of Climate, 11 (11), 2858-2862. https://doi.org/10.1175/1520-0442(1998)011\%3C2858:ARITIT\%3E2.0.CO;2

Ghorbani, M. A., Asadi, H., Makarynskyy, O., Makarynska, D., \& Yaseen, Z. M. (2017). Augmented chaosmultiple linear regression approach for prediction of wave parameters. Engineering science and technology, an international journal , 20 (3), 1180-1191. https://doi.org/10.1016/j.jestch.2016.12.001

Ghorbani, M. A., Khatibi, R., Sivakumar, B., \& Cobb, L. (2010). Study of discontinuities in hydrological data using catastrophe theory. Hydrological Sciences Journal-Journal des Sciences Hydrologiques , 55 (7), 1137-1151. https://doi.org/10.1080/02626667.2010.513477

Grassberger, P., \& Procaccia, I. (1983a). Measuring the strangeness of strange attractors. Physica D , 9 , 189-208.

Grassberger, P., \& Procaccia, I. (1983b). Estimation of the Kolmogorov entropy from a chaotic signal. Physical Review, 28 (4), 2591.

Hamilton, S. K. (2010). Biogeochemical implications of climate change for tropical rivers and floodplains. Hydrobiologia ,657 (1), 19-35. 
Hastings, A., Hom, C. L., Ellner, S., Turchin, P., \& Godfray, H. C. J. (1993). Chaos in ecology: is mother nature a strange attractor? Annual Review of Ecology and Systematics, 24 (1), 1-33.

Huisman, J., \& Weissing, F. J. (1999). Biodiversity of plankton by species oscillations and chaos. Nature, 402 (6760), 407-410.

Hurst, H. E. (1951). Long-term storage capacity of reservoirs. Transactions of the American society of civil engineers , 116 , 770-799. https://doi.org/10.1061/TACEAT.0006518

Jardim, P. F., Melo, M. M. M., Ribeiro, L. D. C., Collischonn, W., \& Paz, A. R. D. (2020). A modeling assessment of large-scale hydrologic alteration in south american Pantanal due to upstream dam operation.Frontiers in Environmental Science , 8, 15.

Junk, W. J., Bayley, P. B., \& Sparks, R. E. (1989). The flood pulse concept in river-floodplain systems. Canadian Special Publication of Fisheries and Aquatic Sciences, 106 (1), 110-127.

Kantz, H., \& Schreiber, T. (2004). Nonlinear time series analysis (Vol. 7). Cambridge university press.

Kantz, H., \& Schreiber, T. (1997). Non-Linear Time Series Analysis, Cambridge Non-linear Science: Series 7, Cambridge University Press, New York.

Kauffman, S. A. (1993). The origins of order: Self-organization and selection in evolution. Oxford University Press, USA.

Kedra, M. (2014). Deterministic chaotic dynamics of raba river flow (polish carpathian mountains). Journal of Hydrology , 509 , 474-503. https://doi.org/10.1016/j.jhydrol.2013.11.055

Khatibi, R., Ghorbani, M. A., Aalami, M. T., Kocak, K., Makarynskyy, O., Makarynska, D., \& Aalinezhad, M. (2011). Dynamics of hourly sea level at Hillarys Boat Harbour, Western Australia: a chaos theory perspective.Ocean Dynamics , 61 (11), 1797-1807. DOI: 10.1007/s10236-011-0466-8

Khatibi, R., Sivakumar, B., Ghorbani, M. A., Kisi, O., Koçak, K., \& Zadeh, D. F. (2012). Investigating chaos in river stage and discharge time series. Journal of Hydrology , $414,108-117$. https://doi.org/10.1016/j.jhydrol.2011.10.026

Khokhlov, V., Glushkov, A., Loboda, N., Serbov, N., \& Zhurbenko, K. (2008). Signatures of low-dimensional chaos in hourly water level measurements at coastal site of Mariupol, Ukraine. Stochastic Environmental Research and Risk Assessment , 22 (6), 777-787. DOI: 10.1007/s00477-007-0186-2

Kiladis, G. N., \& Diaz, H. F. (1989). Global climatic anomalies associated with extremes in the Southern Oscillation. Journal Climate , 2 (9), 1069-1090. https://doi.org/10.1175/15200442(1989)002\%3C1069:GCAAWE\%3E2.0.CO;2

Krakovská, A., Mezeiová, K., \& Budáčová, H. (2015). Use of false nearest neighbours for selecting variables and embedding parameters for state space reconstruction. Journal of Complex Systems . https://doi.org/10.1155/2015/932750

Labat, D., Ronchail, J., \& Guyot, J. L. (2005). Recent advances in wavelet analyses: Part 2-Amazon, Parana, Orinoco and Congo discharges time scale variability. Journal of Hydrology , 314 (1-4), 289-311. https://doi.org/10.1016/j.jhydrol.2005.04.004

Lee, E., Livino, A., Han, S. C., Zhang, K., Briscoe, J., Kelman, J., \& Moorcroft, P. (2018). Land cover change explains the increasing discharge of the Paraná River. Regional Environmental Change, 18 (6), 1871-1881.

Lewin, R. (1999). Complexity: Life at the edge of chaos. University of Chicago Press.

Luo, X., Nakamura, T., \& Small, M. (2005). Surrogate test to distinguish between chaotic and pseudoperiodic time series. Physical Review E , 71 (2), 026230. https://doi.org/10.1103/PhysRevE.71.026230 
Ma, W., Kang, Y., \& Song, S. (2020). Analysis of Streamflow Complexity Based on Entropies in the Weihe River Basin, China. Entropy ,22 (1), p.38.

Maftei, C., Barbulescu, A., \& Carsteanu, A. A. (2016) Long-range dependence in the time series of Taiţa River discharges.Hydrological Sciences Journal , 61 (9), 1740-1747. DOI: 10.1080/02626667.2016.1171869

Marchetti, Z. Y., Ramonell, C. G., Brumnich, F., Alberdi, R., \& Kandus, P. (2020). Vegetation and hydrogeomorphic features of a large lowland river: NDVI patterns summarizing fluvial dynamics and supporting interpretations of ecological patterns. Earth Surface Processes and Landforms, 45, 694-706. https://doi.org/10.1002/esp.4766

Marwan, N., Romano, M. C., Thiel, M., \& Kurths, J. (2007). Recurrence plots for the analysis of complex systems. Physics reports , 438 (5-6), 237-329. https://doi.org/10.1016/j.physrep.2006.11.001

Mayora, G., Scarabotti, P., Schneider, B., Alvarenga, P., \& Marchese, M. (2020). Multiscale environmental heterogeneity in a large river-floodplain system. Journal of South American Earth Sciences, 100 , 102546.

McManamay, R. A., Bevelhimer, M. S., \& Kao, S. C. (2014). Updating the US hydrologic classification: an approach to clustering and stratifying ecohydrologic data. Ecohydrology , 7 (3), 903-926. https://doi.org/10.1002/eco.1410

Mechoso, C. R., \& Perez Iribarren, G. (1992). Streamflow in southeastern South America and the southern oscillation. Journal of climate , 5 (12), 1535-1539. https://doi.org/10.1175/15200442(1992)005\%3C1535:SISSAA\%3E2.0.CO;2

Medvinsky, A. B., Petrovskii, S. V., Tikhonov, D. A., Tikhonova, I. A., Ivanitsky, G. R., Venturino, E., \& Malchow, H. (2001). Biological factors underlying regularity and chaos in aquatic ecosystems: simple models of complex dynamics. Journal of biosciences, 26 (1), 77-108.

Millen, S., \& Beard, R. (2003). Estimation of the Hurst exponent for the Burdekin River using the HurstMandelbrot rescaled range statistic.

Milliman, J. D., Farnsworth, K. L., Jones, P. D., Xu, K. H., \& Smith, L. C. (2008). Climatic and anthropogenic factors affecting river discharge to the global ocean, 1951-2000. Global and planetary change , 62 (3-4), 187-194. https://doi.org/10.1016/j.gloplacha.2008.03.001

Moreno, C. J. G. (2010). Using the Hurst's exponent as a monitor and predictor of BWR reactor instabilities. Annals of Nuclear Energy , 37 (3), 434-442. https://doi.org/10.1016/j.anucene.2009.12.007

Neiff, J. J. (1990). Ideas para la interpretación ecológica del Paraná.Interciencia, 15 (6), 424-441.

Neiff, J. J., Mendiondo, E. M., \& Depettris, C. A. (2000). ENSO floods on river ecosystems: from catastrophes to myths. River flood defence, kassel reports of hydraulic engineering , 9 , 141-152.

Opperman, J. J., Galloway, G. E., Fargione, J., Mount, J. F., Richter, B. D., \& Secchi, S. (2009). Sustainable floodplains through large-scale reconnection to rivers. Science , 326 (5959), 1487-1488. DOI: $10.1126 /$ science. 1178256

Pasquini, A. I., \& Depetris, P. J. (2007). Discharge trends and flow dynamics of South American rivers draining the southern Atlantic seaboard: An overview. Journal of hydrology , 333 (2-4), 385-399. https://doi.org/10.1016/j.jhydrol.2006.09.005

Peters, E. E. (1994). Fractal market analysis: applying chaos theory to investment and economics (Vol. 24). John Wiley \& Sons.

Pinter, N. (2005). One step forward, two steps back on US floodplains. Science, 308, 207-209.

Poff, N. L., Allan, J. D., Bain, M. B., Karr, J. R., Prestegaard, K. L., Richter, B. D., Sparks, R. E., \& Stromberg J.C. (1997). The natural flow regime: a paradigm for river conservation and restoration.BioScience , 47 (11), 769-784. https://doi.org/10.2307/1313099 
Poff, N. L., Tharme, R. E., \& Arthington, A. H. (2017). Evolution of environmental flows assessment science, principles, and methodologies. In: Water for the Environment (pp. 203-236). Editor(s): A. C., Horne, J. A., Webb, M. J., Stewardson, B., Richter, M., Acreman. Academic Press. https://doi.org/10.1016/B978-0-12803907-6.00011-5.

Poff, N. L., Olden, J. D., Pepin, D. M., \& Bledsoe, B. P. (2006). Placing global stream flow variability in geographic and geomorphic contexts. River Research and Applications, 22 (2), 149-166.

Porporato, A., \& Ridolfi, L. (1997). Nonlinear analysis of river flow time sequences. Water Resources Research , 33 (6), 1353-1367. https://doi.org/10.1029/96WR03535

Power, M. E. (1995). Floods, food chains and ecosystem processes in rivers. In: Jones, C. L., \& Lawton J. H. (eds.), Linking species and ecosystems. Chapman and Hall, New York.

Probst, J. L., \& Tardy, Y. (1989). Global runoff fluctuations during the last 80 years in relation to world temperature change.American journal of science , 289 , 267-285. http://dx.doi.org/10.2475/ajs.289.3.267

Puckridge, J. T., Sheldon, F., Walker, K. F., \& Boulton, A. J. (1998). Flow variability and the ecology of large rivers. Marine and freshwater research , 49 (1), 55-72.

Puig, A., Olguín Salinas, H., \& Borús, J. A. (2016). Recent changes (1973-2014 versus 1903-1972) in the flow regime of the Lower Paraná River and current fluvial pollution warnings in its Delta Biosphere Reserve. Environmental Science and Pollution Research ,23 (12), 11471-11492. DOI: 10.1007/s11356-016-6501-z

R Core Team (2021). R: A language and environment for statistical computing. R Foundation for Statistical Computing, Vienna, Austria. URL https://www.R-project.org/.

Ramonell, C. G., Marchetti, Z., \& Pereira, M. S. (2013). Within-channel levees: a new-recognized fluvial form in the floodplain of a large river (Paraná River, South America). 8th International conference (AIG) on Geomorphology.

Ramonell, C.G., \& Cristina, I.M. (2014). Geomorfología y propagación de crecidas en el tramo medio del Río Paraná, Argentina. 2do. Congreso Internacional de Hidrología de Llanuras. Santa Fe, Argentina.

Robertson, A. W., \& Mechoso, C. R. (1998). Interannual and decadal cycles in river flows of southeastern South America. Journal of Climate , 11 (10), 2570-2581. https://doi.org/10.1175/15200442(1998)011\%3C2570:IADCIR\%3E2.0.CO;2

Robledo, F., Vera, C., \& Penalba, O. (2020). Multi-scale features of the co-variability between global sea surface temperature anomalies and daily extreme rainfall in Argentina. International Journal of Climatology, 40 (9), 4289-4299.

Robledo, F. A., Vera, Carolina, \& Olga C. P. (2016). Influence of the large-scale climate variability on daily rainfall extremes over Argentina. International Journal of Climatology, 36 , $412-423$

Ropelewski, C. F., \& Halpert, M. S. (1987). Global and regional scale precipitation patterns associated with the El Nino/Southern Oscillation.Monthly weather review , 115 (8), 1606-1626. https://doi.org/10.1175/1520-0493(1987)115\%3C1606:GARSPP\%3E2.0.CO;2

Rosenstein, M. T., Collins, J. J., \& De Luca, C. J. (1993). A practical method for calculating largest Lyapunov exponents from small data sets.Physica D: Nonlinear Phenomena , 65 (1-2), 117-134. https://doi.org/10.1016/0167-2789(93)90009-P

Salter, G., Voller, V. R., \& Paola, C. (2020). Chaos in a simple model of a delta network. Proceedings of the National Academy of Sciences , 117 (44), 27179-27187. https://doi.org/10.1073/pnas.2010416117

Schreiber, T. (1999). Interdisciplinary application of nonlinear time series methods. Physics reports, 308 (1), 1-64. 
Schumm, S. A., \& Lichty, R. W. (1965). Time, space and causality in geomorphology. American Journal of Science, 263 , 110-119.

Serquina, R., Lai, Y. C., \& Chen, Q. (2008). Characterization of nonstationary chaotic systems. Physical Review E, 77 (2), 026208.

Sivakumar, B. (2000). Chaos theory in hydrology: important issues and interpretations. Journal of hydrology , 227 (1-4), 1-20. https://doi.org/10.1016/S0022-1694(99)00186-9

Sivakumar, B. (2005). Hydrologic modeling and forecasting: role of thresholds. Environmental Modelling $\mathscr{E}$ Software , 20 (5), 515-519. https://doi.org/10.1016/j.envsoft.2004.08.006

Sivakumar, B. (2016). Chaos in hydrology: bridging determinism and stochasticity. Springer . DOI: 10.1007/978-90-481-2552-4

Sivakumar, B., \& Jayawardena, A. W. (2002). An investigation of the presence of low-dimensional chaotic behaviour in the sediment transport phenomenon. Hydrological Sciences Journal , 47 (3), 405-416. http://dx.doi.org/10.1080/02626660209492943

Sivakumar, B., \& Singh, V. P. (2012). Hydrologic system complexity and nonlinear dynamic concepts for a catchment classification framework.Hydrology and Earth System Sciences , 16 (11), 4119-4131. https://doi.org/10.5194/hess-16-4119-2012

Sivakumar, B., Jayawardena, A. W., \& Li, W. K. (2007). Hydrologic complexity and classification: a simple data reconstruction approach.Hydrological Processes: An International Journal , 21 (20), 2713-2728. https://doi.org/10.1002/hyp.6362

Soetaert, K. (2021). Plotting Multi-Dimensional Data. 'plot3D' R package. Version 1.0.2.

Sturman, A. P., \& Tapper, N. J. (1996). The weather and climate of Australia and New Zealand . Oxford University Press, USA.

Tabacchi, E., Correll, D. L., Hauer, R., Pinay, G., Planty-Tabacchi, A. M., \& Wissmar, R. C., (1998). Development, maintenance and role of riparian vegetation in the river landscape. Freshwater biology, 40 (3), 497-516.

Takens, F. (1981). Detecting strange attractors in turbulence. In Dynamical systems and turbulence, Warwick. Springer, 366-381. http://dx.doi.org/10.1007/bfb0091924

Tavares Lima, I. B., Rosa, R. R., Ramos, F. M., \& de Moraes Novo, E. M. L. (2003). Water level dynamics in the Amazon floodplain. Advances in water resources, 26(7), 725-732.

Taylor, R.L., 2010. Attractors: Nonstrange to chaotic. Society for Industrial and Applied Mathematics, Undergraduate Research Online, 72-80.

Theiler, J., Eubank, S., Longtin, A., Galdrikian, B., \& Farmer, J. D. (1992). Testing for nonlinearity in time series: the method of surrogate data. Physica D: Nonlinear Phenomena , 58 (1-4), 77-94. https://doi.org/10.1016/0167-2789(92)90102-S

Thomaz, S. M., Bini, L. M., \& Bozelli, R. L. (2007). Floods increase similarity among aquatic habitats in river-floodplain systems. Hydrobiologia, 579 (1), 1-13.

Thorp, J. H., Thoms, M. C., \& Delong, M. D. (2006). The riverine ecosystem synthesis: biocomplexity in river networks across space and time. River Research and Applications , 22 (2), 123-147. https://doi.org/10.1002/rra.901

Tongal, H., \& Berndtsson, R. (2014). Phase-space reconstruction and self-exciting threshold modeling approach to forecast lake water levels.Stochastic environmental research and risk assessment ,28 (4), 955-971. DOI: $10.1007 / \mathrm{s} 00477-013-0795-\mathrm{x}$ 
Tossini, L. (1959). Sistema hidrografico y cuenca del Rio de la Plata: contribucion al estudio de su regimen hidrologico (No. ANA soc-cie).

Viglizzo, E. F., \& Frank, F. C. (2006). Land-use options for Del Plata Basin in South America: Tradeoffs analysis based on ecosystem service provision. Ecological economics , 57 (1), 140-151. https://doi.org/10.1016/j.ecolecon.2005.03.025

Ward, J. V., \& Stanford, J. A. (1995). Ecological connectivity in alluvial river ecosystems and its disruption by flow regulation. Regulated rivers: research $\& 3$ management, 11 (1), 105-119.

Ward, J. V., Tockner, K., \& Schiemer, F. (1999). Biodiversity of floodplain river ecosystems: ecotones and connectivity1. River Research and Applications, 15 (1-3), 125-139.

Webb, J. A., Stewardson, M. J., \& Koster, W. M. (2010). Detecting ecological responses to flow variation using Bayesian hierarchical models. Freshwater Biology , 55 (1), 108-126. https://doi.org/10.1111/j.13652427.2009.02205.x

Weron, R. (2002). Estimating long-range dependence: finite sample properties and confidence intervals. Physica A: Statistical Mechanics and its Applications , 312 (1-2), 285-299. https://doi.org/10.1016/S0378-4371(02)00961-5.

Wilks, D. S. (1991). Representing serial correlation of meteorological events and forecasts in dynamic decision-analytic models. Monthly Weather Review , 119 (7), 1640-1662. https://doi.org/10.1175/15200493(1991)119\%3C1640:RSCOME\%3E2.0.CO;2

Xavier, A. C. F., Rudke, A. P., Fujita, T., Blain, G. C., de Morais, M. V. B., de Almeida, D. S., ... \& Martins, J. A. (2020). Stationary and non-stationary detection of extreme precipitation events and trends of average precipitation from 1980 to 2010 in the Parana River basin, Brazil. International Journal of Climatology, 40 (2), 1197-1212.

Zanon, J. E. (2021). Annual cycle dampening and decrease in predictability of water level fluctuations in a dam-regulated Neotropical floodplain. Hydrobiologia , 1-15. DOI: 10.1007/s10750-021-4656-

Žibret, G., \& Verbovšek, T. (2009). Quantitative analysis of randomness exhibited by river channels using chaos game technique: Mississippi, Amazon, Sava and Danube case studies. Nonlinear Processes in Geophysics, 16 (3), 419-429.

Zounemat-Kermani, M., (2016). Investigating chaos and nonlinear forecasting in short term and mid-term river discharge. Water resources management, 30 (5), 1851-1865.

\section{FIGURE LEGENDS}

Figure 1. The Paraná River and its tributaries (plotted in blue), location of the gauging stations studied (a: Itatí, b: Corrientes, c: Túnel Subfluvial), and La Plata Basin domain in South America. Landsat images (December 2017) from Google Earth Pro visualizing the Paraná River at each gauging station. Daily water level fluctuations from 1910 to 2015 in Itatí (a), from 1904 to 1990 in Corrientes (b), and from 1904 to 2015 in Túnel Subfluvial (c) stations.

Figure 2. Power spectrum of temporal daily water level of the Paraná River at the three gauging stations (a: Itatí; b: Corrientes; c: Túnel Subfluvial).

Figure 3. Three-dimensional phase-space reconstructions of the time series of the Paraná River water level at the three gauging stations (a: Itatí; b: Corrientes; c: Túnel Subfluvial). The points of trajectories are connected for better visualization of the 'evolution' of the system dynamic.

Figure 4. Correlation dimension of the daily water level time series of the Paraná River at the three gauging stations (a: Itatí; b: Corrientes; c: Túnel Subfluvial). The saturation of the D2 after an increase of the embedding dimension $\mathrm{m}$ reveals that the system is chaotic. 
Figure 5. Estimation of maximum Lyapunov exponent on the basis of different embedding dimensions calculated on the water level time series of the Paraná River at three gauging stations (a: Itatí; b: Corrientes; c: Túnel Subfluvial), for different embedding dimensions $\mathrm{m}$ ( $\mathrm{m}=13$ to 28 indicated with different line colours).

Figure 6. Recurrence plots as proposed by Eckmann et al.(1987), showing the distribution of Nij points represented in black (defined as cero, that means minimum distance) and in white (defined as one that means maximum distance or major transition) characterizing the trajectory in the state space of our system at the three gauging stations.

\section{SIGNIFICANCE STATEMENT}

This work constitutes the first study of the hydrological regime of one of the largest rivers of the world (the floodplain of the Paraná River) using models that consider chaotic behaviour. We applied several analyses on daily water level during the last century at three gauging stations. Evidence shows that the hydrological dynamic behaves at the edge of chaos and presents a non-stationary and intermediate complexity. The study of hydrological processes is fundamental for a proper planning and managing of rivers and for understanding the underlying processes that drive ecological functions and biodiversity assembly.

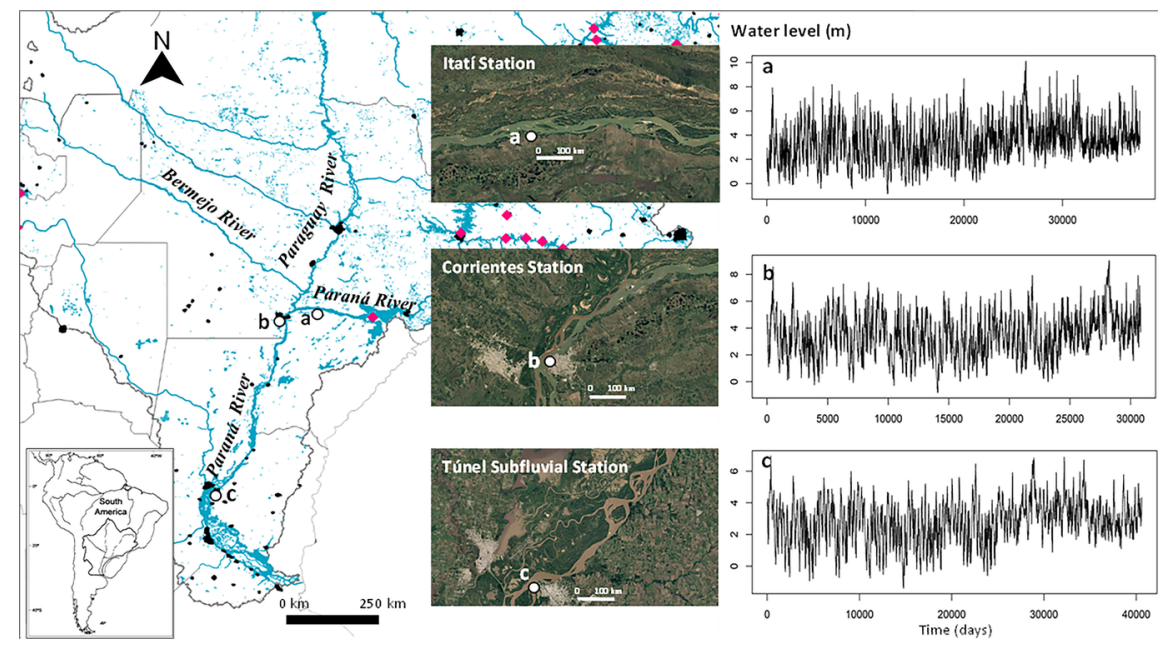



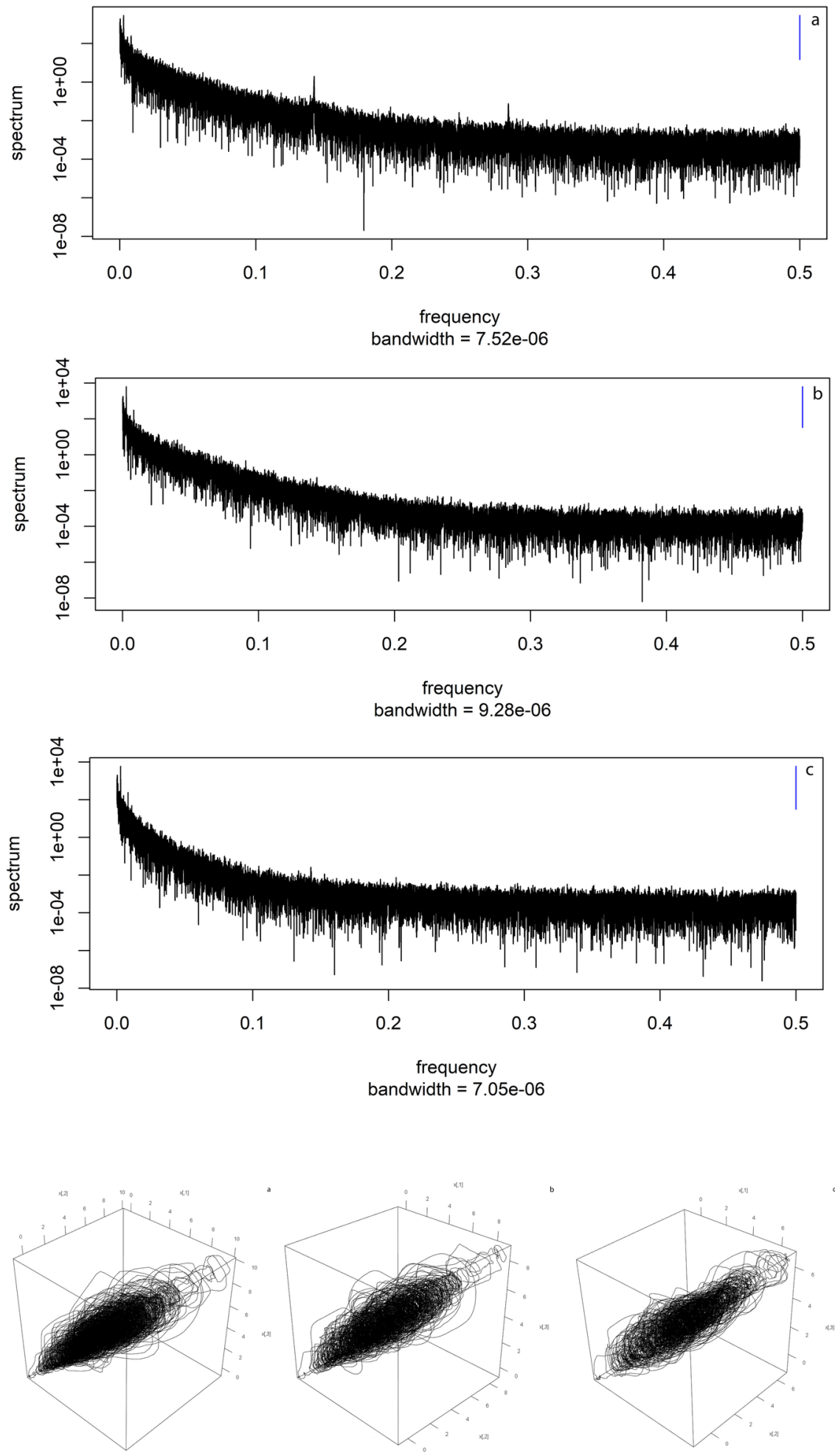

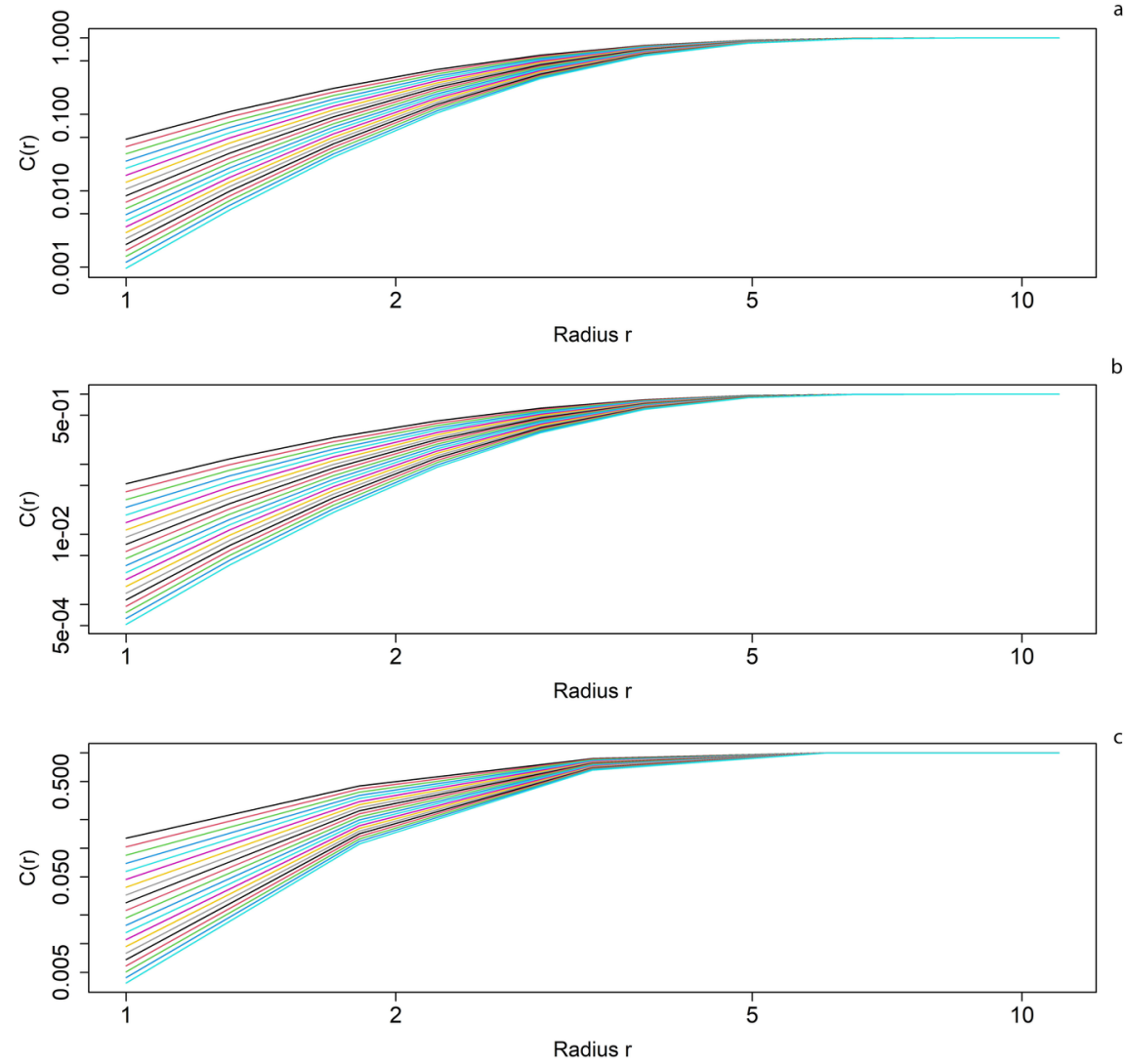

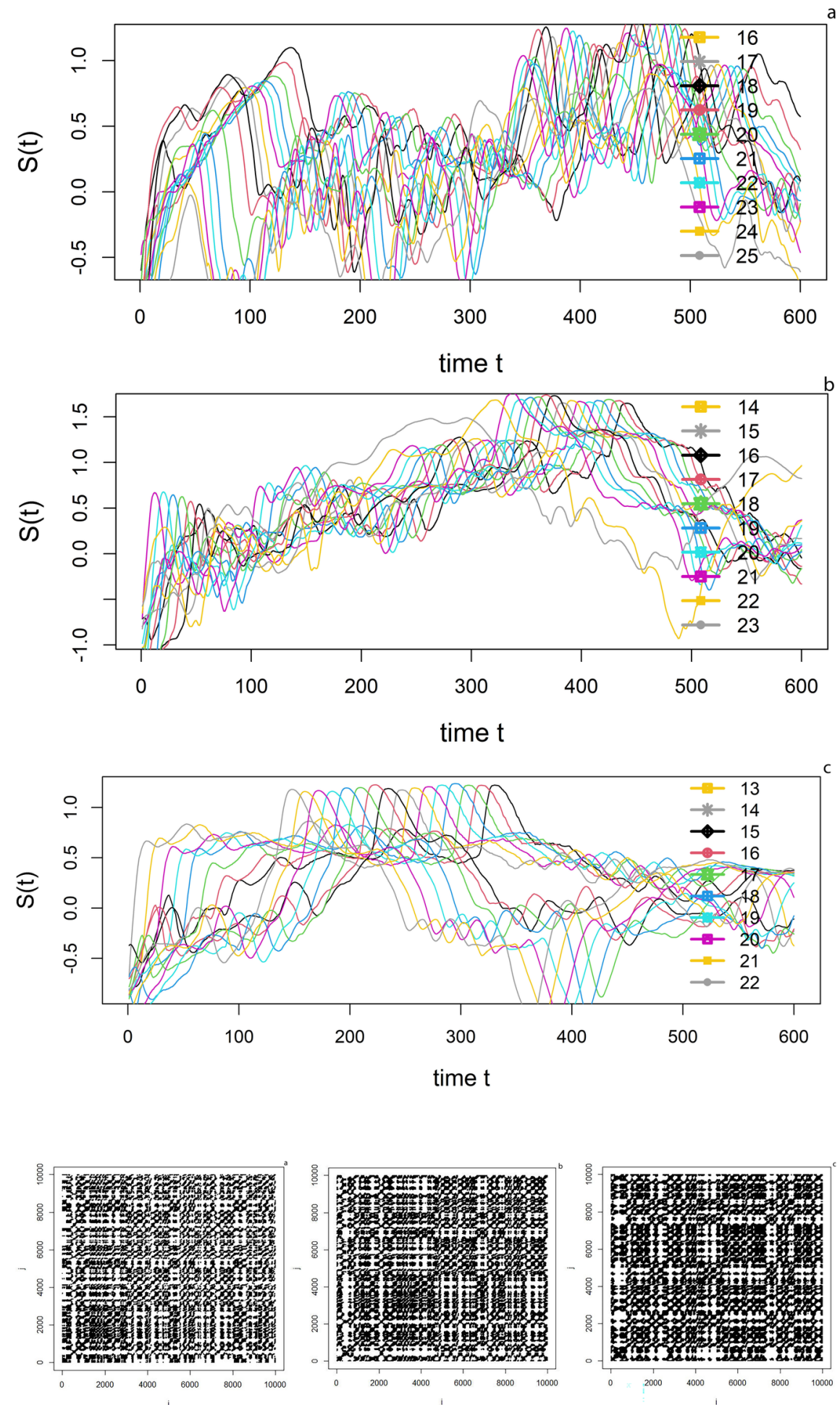

\section{Hosted file}

Table 1.docx available at https://authorea.com/users/445753/articles/545165-chaos-arisingfrom-the-hydrological-behaviour-of-a-floodplain-river-during-the-last-century 


\section{Hosted file}

Table 2.docx available at https://authorea.com/users/445753/articles/545165-chaos-arisingfrom-the-hydrological-behaviour-of-a-floodplain-river-during-the-last-century 